\title{
Deletion of the glucocorticoid receptor chaperone FKBP51 prevents glucocorticoid-induced skin atrophy
}

\author{
Gleb Baida ${ }^{1}$, Pankaj Bhalla ${ }^{1}$, Alexander Yemelyanov ${ }^{2}$, Lance A. Stechschulte ${ }^{3}$, \\ Weinian Shou ${ }^{4}$, Ben Readhead ${ }^{5,6}$, Joel T. Dudley ${ }^{5,6}$, Edwin R. Sánchez ${ }^{3}$ and Irina \\ Budunova $^{1}$ \\ ${ }^{1}$ Department of Dermatology, Northwestern University, Chicago, IL, USA \\ ${ }^{2}$ Department of Medicine, Pulmonary Division, Northwestern University, Chicago, IL, USA \\ ${ }^{3}$ Department of Physiology \& Pharmacology, The Center for Diabetes and Endocrine Research, University of Toledo College \\ of Medicine, Toledo, OH, USA \\ ${ }^{4}$ Wells Center for Pediatric Research, Indiana University School of Medicine, Indianapolis, IN, USA \\ ${ }^{5}$ Department of Genetics and Genomic Sciences, Icahn School of Medicine at Mount Sinai, New York, NY, USA \\ ${ }^{6}$ Institute for Next Generation Healthcare, Mount Sinai Health System, New York, NY, USA \\ Correspondence to: Irina Budunova, email: i-budunova@northwestern.edu \\ Keywords: glucocorticoid; glucocorticoid receptor; skin atrophy; FKBP51; Akt
}

Received: July 27, $2018 \quad$ Accepted: September 15, $2018 \quad$ Published: October 05, 2018

Copyright: Baida et al. This is an open-access article distributed under the terms of the Creative Commons Attribution License 3.0 (CC BY 3.0), which permits unrestricted use, distribution, and reproduction in any medium, provided the original author and source are credited.

\section{ABSTRACT}

FKBP51 (FK506-binding protein 51) is a known co-chaperone and regulator of the glucocorticoid receptor (GR), which usually attenuates its activity. FKBP51 is one of the major GR target genes in skin, but its role in clinical effects of glucocorticoids is not known. Here, we used FKBP51 knockout (KO) mice to determine FKBP51's role in the major adverse effect of topical glucocorticoids, skin atrophy. Unexpectedly, we found that all skin compartments (epidermis, dermis, dermal adipose and CD34+ stem cells) in FKBP51 KO animals were much more resistant to glucocorticoid-induced hypoplasia. Furthermore, despite the absence of inhibitory FKBP51, the basal level of expression and glucocorticoid activation of GR target genes were not increased in FKBP51 KO skin or CRISPR/Cas9-edited FKBP51 KO HaCaT human keratinocytes. FKBP51 is known to negatively regulate Akt and mTOR. We found a significant increase in AktSer473 and mTORSer2448 phosphorylation and downstream pro-growth signaling in FKBP51deficient keratinocytes in vivo and in vitro. As Akt/mTOR-GR crosstalk is usually negative in skin, our results suggest that Akt/mTOR activation could be responsible for the lack of increased GR function and resistance of FKBP51 KO mice to the steroidinduced skin atrophy.

\section{INTRODUCTION}

Glucocorticoid hormones (Gcs) are steroid hormones mostly produced in the adrenal cortex. However, they can be also synthesized locally in different tissues including skin which expresses the genes for enzymes involved in glucocorticoid biosynthesis [1-3]. Gcs are well known physiological and pharmacological regulators of metabolism, proliferation, differentiation and inflammation in skin [4], and the decreased amount of endogenous Gcs in skin is now linked to the skin diseases such as psoriasis [5].

The synthetic Gcs were introduced as potent antiinflammatory drugs in 1950-s, and remain the frontline for the treatment of inflammatory skin diseases, including psoriasis and atopic dermatitis [6, 7]. Unfortunately, chronic treatment with Gcs induces numerous adverse effects including cutaneous atrophy, which involves all skin compartments and results in overall skin thinning, reduction in size and number of keratinocytes, inhibition 
of dermal fibroblast proliferation and collagen synthesis, and atrophy of sebaceous glands, hair follicles and dermal adipose [8-10]. Although these morphological changes are well documented, the molecular mechanisms underlying development of skin atrophy are not well understood.

The effects of glucocorticoids are mediated by the glucocorticoid receptor (GR), a well-characterized transcription factor and member of the nuclear receptor family. In unstimulated cells, GR resides in cytoplasm bound to chaperones including heat shock proteins and immunophilins, such as FKBP51 (FK506-binding protein 51), which control GR activation and nuclear import [11]. Upon hormone binding, GR translocates to the nucleus where it regulates gene expression positively via binding to glucocorticoid response elements of target genes; or negatively via different mechanisms, including tethering - binding to other transcription factors, such as NF- $\kappa \mathrm{B}$, to modulate their activity [11]. In addition, GR can modulate in DNA-binding independent manner the pro-proliferative/ pro-survival signaling mediated by phosphatidylinositol 3-kinase (PI3K), Akt, mTOR, and mitogen-activated protein kinases (MAPKs) [11-13].

We and others found that FKBP51 is a major GR target gene in skin, as it was strongly up-regulated in keratinocytes of skin-specific keratin5 (K5)-GR transgenics and down-regulated in GR knockout (KO) mice $[14,15]$. FKBP51 is a member of FK506-binding protein (Fkbp) family. Like all immunophilins, FKBP51 has peptidyl-prolyl isomerase (PPIase) activity and is involved in immunoregulation, protein folding and trafficking [16]. As a molecular chaperone, FKBP51 has numerous clients including steroid receptors. In the case of GR, interaction with FKBP51 interferes with receptor maturation, reduces ligand-binding affinity and impairs GR nuclear import $[17,18]$. Binding of ligand to GR favors replacement of FKBP51 with FKBP52, which then increases GR affinity to glucocorticoids, dimerization and nuclear transport [19].

FKBP51 is also known to control Akt, mTOR, and $\mathrm{NF}-\kappa \mathrm{B}$ pathways that in turn, negatively crosstalk with GR. Growth factor-dependent, full Akt activation requires phosphorylation at Thr308 and Ser473 [20]. FKBP51 acts as a scaffolding protein to enhance the interaction of the phosphatases PHLPP1/2 with Akt, which results in dephosphorylation of Ser473 [21, 22]. FKBP51 also binds to mTOR and inhibits its kinase activity as potently as rapamycin with its accessory partner FKBP12 [23]. In addition, FKBP51 impairs both NF- $\kappa$ B's nuclear translocation and transcriptional activity [24, 25]. The role of FKBP51 in the effects of topical glucocorticoids in skin has not been studied. Here, we confirmed FKBP51 induction by glucocorticoids in mouse and human skin, and used FKBP51 KO mice [26] to determine the role of FKBP51 in glucocorticoid-induced skin atrophy.

As FKBP51 is a major negative GR regulator, the possible outcomes in FKBP51 KO animals could be elevated GR activity and enhanced anti-proliferative effects of endogenous/exogenous glucocorticoids. However, we found that FKBP51 KO mice had modest epidermal hyperplasia and were much more resistant to skin atrophy induced by chronic treatment with the glucocorticoid fluocinolone acetonide (FA) than wild type mice. This effect in FKBP51 KO mice was seen despite the lack of changes in GR activity. We also found that Akt and mTOR were constitutively activated in FKBP51 KO skin and in HaCaT human keratinocytes lacking FKBP51. Taken as a whole, our results suggest that FKBP51 acts as an atrophogene during chronic skin treatment with steroids in part by inhibiting Akt/mTOR activity.

\section{RESULTS}

\section{Topical glucocorticoids induce FKBP51 expression}

FKBP51 is a GR target gene $[14,15]$. However, the effect of glucocorticoids on FKBP51 in skin has not been well studied. We used a medium potency glucocorticoid fluocinolone acetonide (FA) to topically treat wild type F1 C57Bl x 129 mice, and a highly potent glucocorticoid clobetasol propionate (CBP) to treat human volunteers. The glucocorticoid doses and regimens used induce significant mouse and human skin atrophy, as shown previously [14, 27].

In mouse and human skin, the basal level of FKBP51 expression in epidermis and skin appendages was low (Figure 1). In mice, FKBP51 expression was strongly induced at mRNA and protein levels $8 \mathrm{~h}$ after FA application, and remained elevated during 2 wk treatment (Figure 1a-1c). FKBP51 protein was expressed in interfollicular epidermis, hair follicles and sebaceous glands in FA-treated skin (Figure 1c). Glucocorticoidsinduced hypoplastic changes in mouse epidermis are always paralleled by the severe atrophy of dermal adipose [27], (Figure 2). Thus, we assessed FKBP51 expression in subcutaneous adipose mechanically separated from other skin tissues. The purity of adipose isolations was verified using specific adipocyte and keratinocyte markers (Supplementary Figure 1). We found strong, comparable to epidermis, induction of FKBP51 mRNA in adipose (Figure 1b).

To complement the animal study, we assessed the effect of glucocorticoid CBP on FKBP51 in human skin. We detected strong induction of FKBP51 mRNA and protein in human skin $24 \mathrm{~h}$ after CBP application (Figure 1d, 1e).

\section{Skin phenotype of FKBP51 KO mice}

To determine the role of FKBP51 in glucocorticoidinduced skin atrophy, we used FKBP51 KO mice (B1 x 129 genetic background) that have no overt phenotype 
if untreated [26]. Interestingly, FKBP51 KO mouse skin was characterized by a modest, but significant, epidermal hyperplasia (Supplementary Figure 2a, 2c, 2d) and increased keratinocyte proliferation. In nontreated females the BrdU+ labeling indices were 4.2\%+/1.6 and $6.25 \%+/-2.5$ in WT and FKBP51 KO mice accordingly (t-statistic, $\mathrm{P}<0.001$ ). In males, there was also a trend to the increase in BrdU index in FKBP51 KO animals: $4.3 \% \pm 1.5$ in FKBP51 KO versus $2.7 \% \pm 1.5$ in WT epidermis (t-statistic, $\mathrm{P}=0.065$ ). We also observed alteration of hair follicle morphology - unusual dilation of infundibulum frequently filled with flocculent mixture, especially in males (Supplementary Figure 2a, 2e). At the same time, there were no changes in the expression of keratinocyte differentiation markers K5, K10 and loricrin (Supplementary Figure 2b), suggesting that FKBP51 is involved in keratinocyte proliferation but not required for normal keratinocyte differentiation.

\section{Resistance of FKBP51 KO mice to glucocorticoid-induced skin atrophy}

FKBP51 is a negative GR regulator, thus we expected that FKBP51 KO animals would be much more sensitive to the effects of glucocorticoids. Unexpectedly, FKBP51 KO mice appeared more resistant to skin atrophy than WT mice when subjected to FA chronic treatment. Epidermal thickness was reduced much less in both female and male KOs (by 16-22\%) compared to WT mice (by $40-45 \%$ ) (t-statistic, $\mathrm{P}<0.001$; Figure $2 \mathrm{a}, 2 \mathrm{~d}$ ). In addition,

a
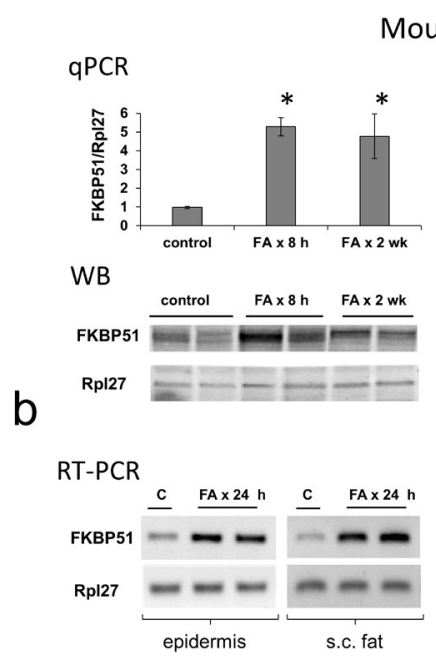

c

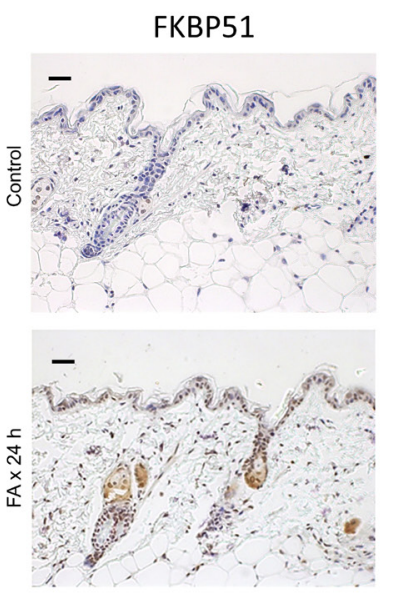

dermal adipose was very strongly protected in the FKBP51 KO animals, especially in males. In females, the dermal adipose thickness was reduced at the end of two week FA treatment by $90 \%$ in WT compared to $60 \%$ in FKBP51 KO animals (Supplementary Figure 4). In males, the protective effect was even more pronounced: dermal adipose thickness was reduced in FA-treated WT skin by $80 \%$ while in FKBP51 KOs only by $10 \%$ (t-statistic $\mathrm{P}<0.001$; Supplementary Figure 4). Interestingly, these results differed from our previous observations that FKBP51 positively controls adipogenesis in vitro, and in gonadal fat depot in vivo [28, 29].

Previously we found that GR activation sharply reduced the number and proliferative potential of epidermal stem cells (SCs) in the hair follicle bulge niche $[14,30]$. Here, WT mice chronically treated with FA also showed almost a complete elimination of CD34 ${ }^{+}$follicular SCs (Figure 2c). Remarkably, in FKBP51 KO mice, the effect of FA on CD34 expression in the bulge was diminished, and $\sim 25 \%$ of hair follicles remained CD34+ (Figure 2c), suggesting that the persistence of bulge SCs may have contributed to the protection of epidermis in $\mathrm{KO}$ mice against steroid atrophy.

The major atrophic effects of topical steroids in dermis include severe thinning of collagen and elastin fibrous networks and decreased dermal cellularity [10]. Masson's trichrome staining, which colors collagen blue, showed strongly reduced collagen fiber density in WT mice in contrast to FKBP51 KOs where effects on fiber network and dermal fibroblasts were minimal (Figure 2b). d e

Human skin

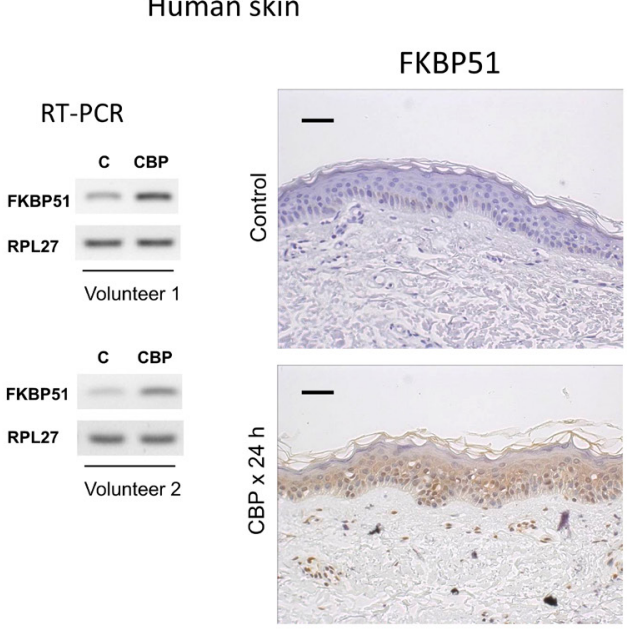

Figure 1: Induction of FKBP51 expression in the skin by glucocorticoids. F1 C57B1 x 129 WT mice were treated topically with acetone (vehicle control, C) or glucocorticoid FA ( $2 \mu \mathrm{g} /$ animal, for $8 \mathrm{~h}, 24 \mathrm{~h}$ or $2 \mathrm{wk})$. Skin of the inner upper arm of human volunteers was treated topically with $0.05 \% \mathrm{CPB}$ cream once for $24 \mathrm{~h}$; untreated skin from the opposite arm was used as control (C). FKBP51 expression was analyzed by qPCR and by Western blotting (WB) in murine epidermis (a), by RT-PCR in epidermis and subcutaneous (s.c.) fat of mice (b), or in whole thickness human skin biopsies (d); Rp127 was used as normalization/loading control. FKBP51 immunostaining of mouse (c) and human (e) skin. Scale bars are $20 \mu \mathrm{m}$ (c) and $40 \mu \mathrm{m}$ (e). ${ }^{*} \mathrm{P}<0.01$, (unpaired two-tailed t-test) for changes compared to corresponding control. 
It is known that genetic background can significantly affect phenotype of transgenic animals. Thus, we assessed the effect of FKBP51 KO on steroid skin atrophy using FKBP51 KO animals in C57Bl background. We found that FKBP51 KO provided even stronger protection against steroid-induced epidermal atrophy in C57Bl mice (Supplementary Figure 3).

\section{Effect of FKBP51 KO on GR activity and mTOR/Akt phosphorylation in skin}

The reduced sensitivity of FKBP51 KO mice to glucocorticoid skin atrophy suggested that lack of FKBP51 could affect GR expression/signaling. We did not find significant changes in GR protein levels in epidermis of untreated FKBP51 KOs (Figure 3a). To assess changes in GR activity, we measured basal and FA-

a

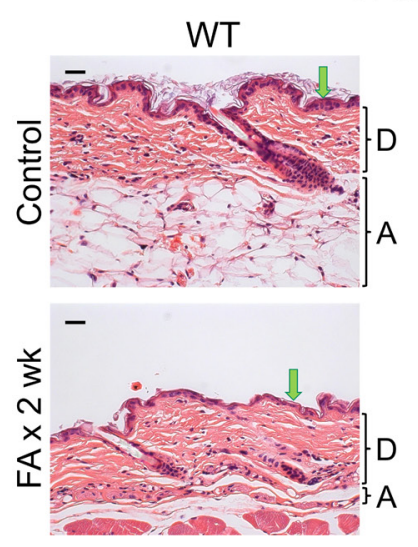

$H \& E$

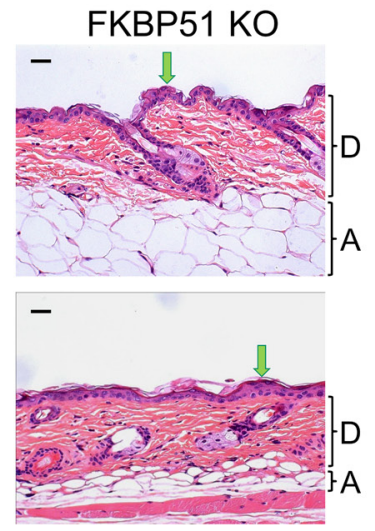

C
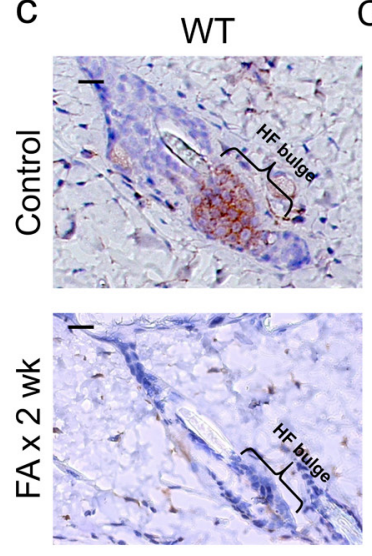

CD34

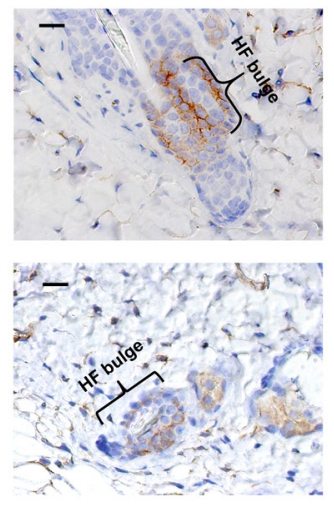

induced expression of known GR-target genes Tsc22d3/ Gilz, Ddit4/Redd1, Cyp2b10, Txnip, Hmgcs2, and Tppp3, [27, 31-33], which were also revealed previously among the differentially expressed genes in skin of B6x129 WT mice treated with FA (our GEO Submission GSE59151). Surprisingly, despite the absence of inhibitory FKBP51, the glucocorticoid activation of these genes in $\mathrm{KO}$ mice was similar to that seen in WT epidermis (Figure 3e).

Other mechanisms by which FKBP51 could modulate GR signaling are through the inhibition of Akt,

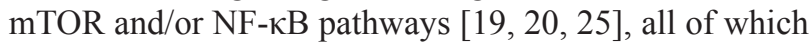
negatively interact with GR signaling at different levels [11-13]. FKBP51 deficiency did not result in significant changes in the expression and phosphorylation of RelA/ $\mathrm{p} 65$, the major NF- $\mathrm{B}$ protein in mouse skin (data not shown). In contrast, we found strongly increased $\mathrm{Akt}^{\mathrm{Ser} 473}$ phosphorylation in the epidermis and appendages of

b

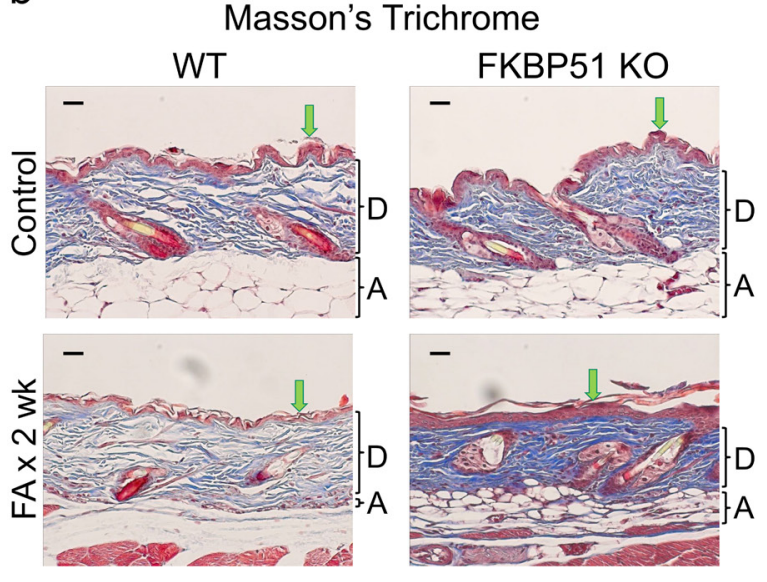

d

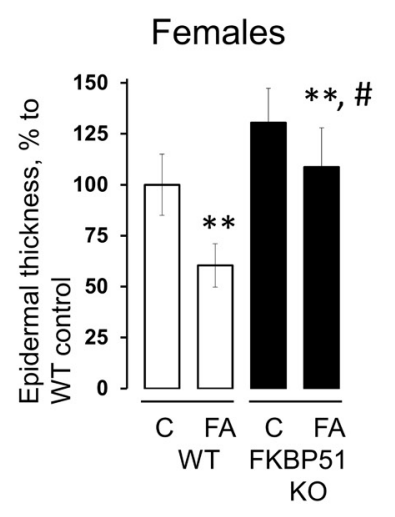

Males

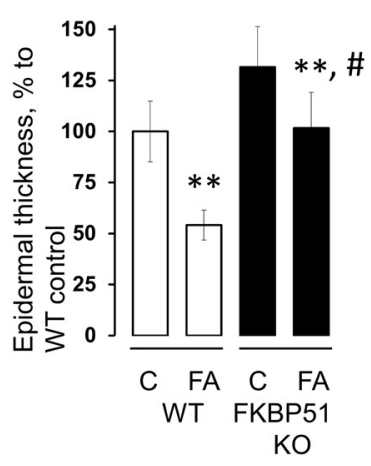

Figure 2: Resistance of FKBP51 KO mice to glucocorticoid-induced skin atrophy. WT and FKBP51 KO male and female mice were treated with vehicle (Control) and FA ( $2 \mu \mathrm{g} /$ animal) for 2 wks. (a) H\&E; (b) Masson's trichrome staining; (c) CD34 immunostaining. Epidermis (green arrows), dermal adipose layer (A), dermis (D) and hair follicle bulge regions (HF bulge) are marked. Scale bars are $20 \mu \mathrm{m}$ (a, b) and $10 \mu \mathrm{m}$ (c). (d) Quantitation of the epidermal thickness in female and male WT and FKBP51 KO mice was performed as described in Materials and Methods. Epidermal thickness is presented as \% to corresponding control epidermis. The means \pm SD were calculated for three individual skin samples in one representative experiment. ${ }^{* *} \mathrm{P}<0.001$, (unpaired two-tailed t-test) for changes compared to corresponding control. ${ }^{\#} \mathrm{P}<0.001$, (unpaired two-tailed t-test) for degree of reduction in epidermal thickness in FKBP51 KO animals compared to WT animals. 
vehicle- and FA-treated FKBP51 KO compared to WT mice, along with increased phosphorylation of $\mathrm{mTOR}^{\mathrm{Ser} 2448}$ (Figure 3c, 3d), the site targeted by Akt and mTOR effector ribosomal p70/S6 kinase1 (S6K1) [34-36]. These results are in agreement with our previous report on the Akt activation in FKBP51 KO murine fibroblasts [37]. We confirmed Akt and mTOR activation and their partial resistance to inhibitory effects of glucocorticoid
FA in the skin of Fkbp51 KO animals using Western blot analysis (Figure 3b). Akt activity was assessed by $\mathrm{Akt}^{\mathrm{Ser} 473}$ phosphorylation, and mTOR activity - by phosphorylation of major mTOR downstream substrate 4E-BP1with easily detectable basal phosphorylation level in skin [38]. Surprisingly, we observed that in FKBP51 KO mice $\mathrm{Akt}^{\mathrm{Ser} 473}$ phosphorylation was increased by $\mathrm{FA}$ at earlier time-point of treatment.

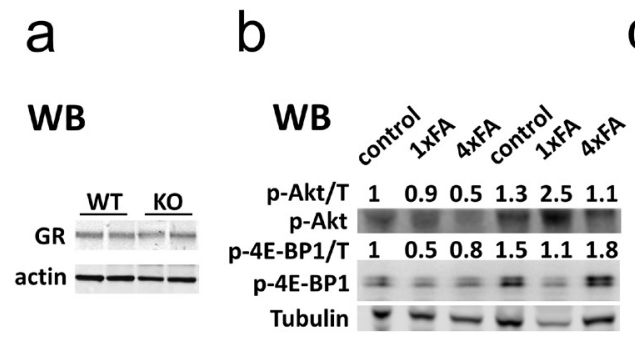

C

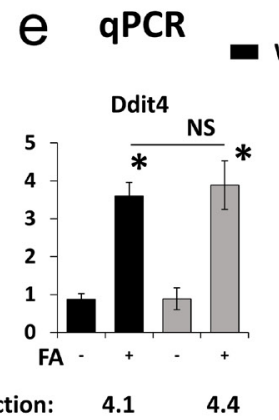

WT $\square$ KO
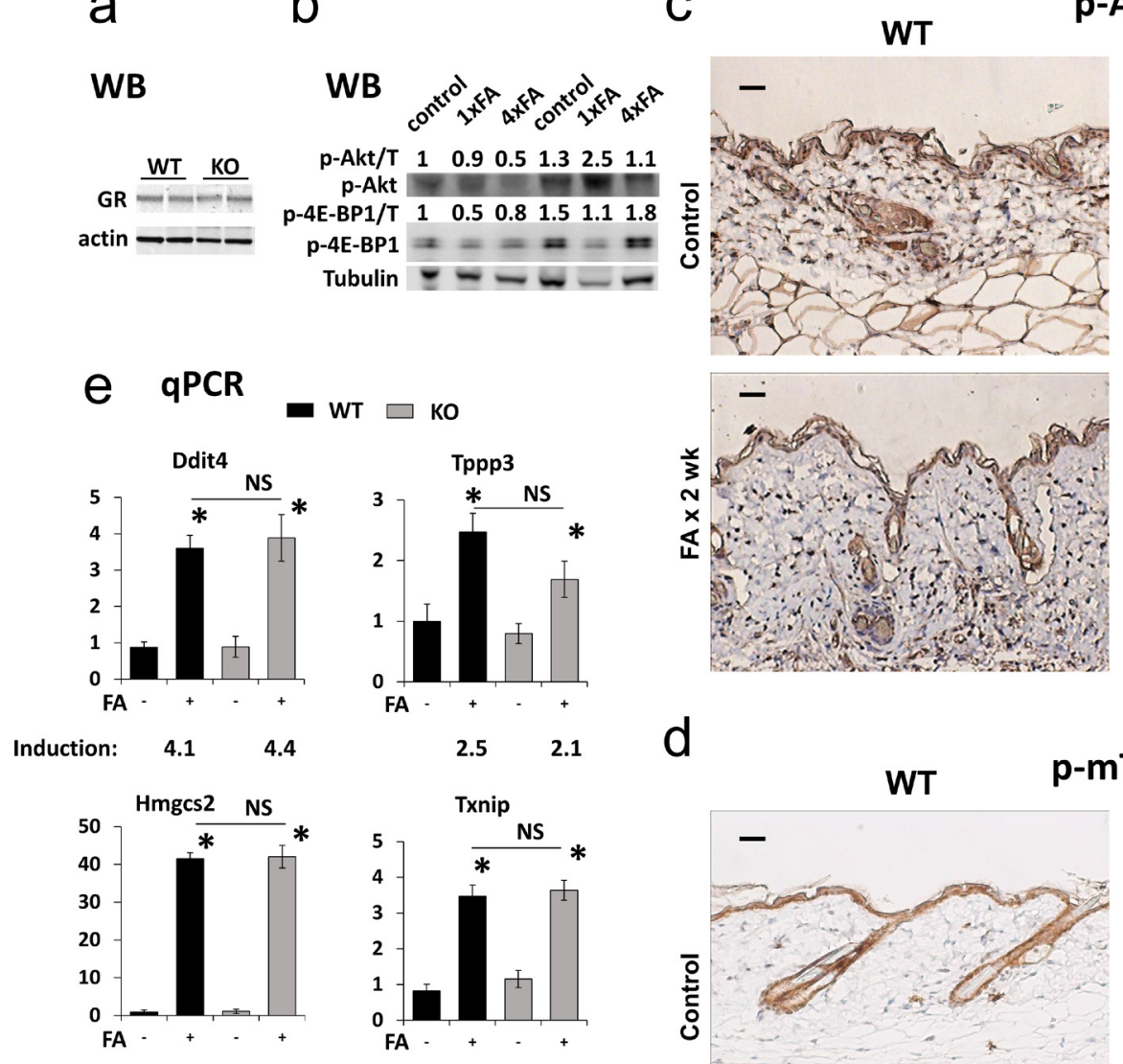

p-Akt FKBP51 KO
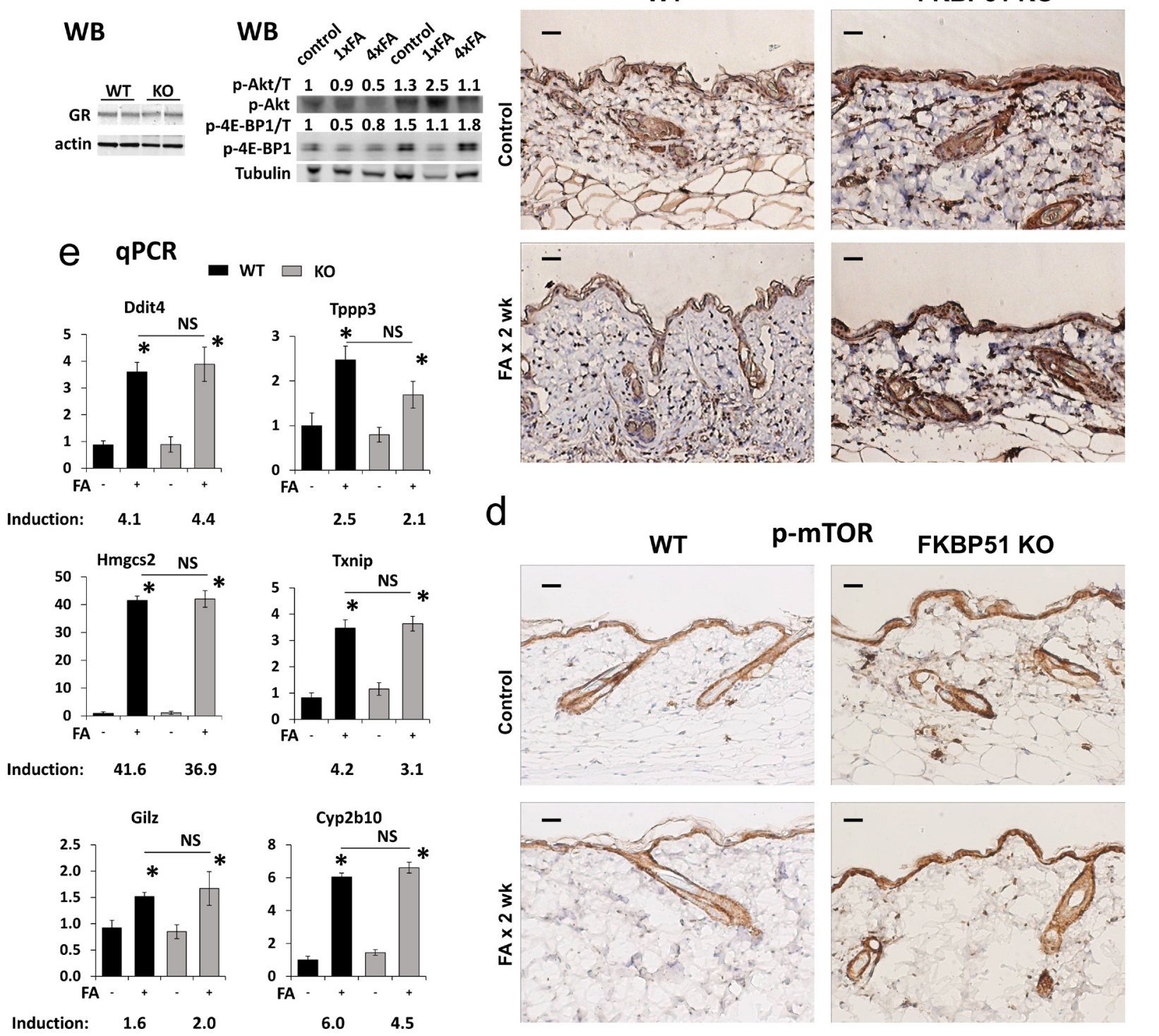


\section{Effects of FKBP51 knockout on GR and Akt/ mTOR function in human keratinocytes in vitro}

To extend our findings and determine whether FKBP51 deficiency affects major steps of GR activation such as phosphorylation and nuclear import/retention, we generated FKBP51 KO keratinocytes using CRISPR/Cas9 technology. Nontumorigenic human HaCaT keratinocytes were transiently transfected with gRNAs in a complex with recombinant Cas9 to knockdown FKBP51 expression (FKBP51 KO-HaCaT). Control cells were transfected with Cas9 only (Figure 4a). Two FKBP51 KO-HaCaT cell lines were established from single cell clones, and used for experiments.

The results of Figure $4 \mathrm{~b}$ show that loss of FKBP51 did not affect the amount of GR or its ability to translocate to the nucleus in response to glucocorticoid FA. Moreover, FA-induced GR phosphorylation at activating Ser211 and nuclear translocation/retention of phosphorylated GR were similar in FKBP51 KO$\mathrm{HaCaT}$ and control HaCaT keratinocytes. We also did not find significant changes in activation of known GR target genes DDIT4/REDD1, KLF9, BEST2, TFCP2L1, and TSC22D3/GILZ [27, 30-32, 38] in FKBP51 KO keratinocytes (Figure 4d). These specific GR target genes were selected from the list of differentially expressed genes in $\mathrm{HaCaT}$ cells treated with FA (our GEO submission GSE97279, [38]).

In good correlation with in vivo results, we observed increased activation of Akt and mTOR after FKBP51 $\mathrm{KO}$ in $\mathrm{HaCaT}$ cells as assessed by phosphorylation of $\mathrm{Akt}^{\mathrm{Ser} 473}, \mathrm{mTOR}^{\mathrm{Ser} 2448}$, and mTOR effector ribosomal p70/ S6 kinase ${ }^{\text {Thr389 }}$ (Figure 4b). At the same time, FKBP51 knockdown in HaCaT cells did not affect NF-kB function monitored by NF-kB protein RelA/p65 phosphorylation and nuclear translocation activated by TNF-a (Figure 4c).

\section{DISCUSSION}

Glucocorticoid-induced skin atrophy represents a serious clinical problem as it leads to debilitating cosmetic effects and compromised skin barrier function [6]. The focus of this study was on the search for the molecular mechanisms underlying skin atrophy. We report here that the induction of FKBP51, a GR target gene involved in negative feedback loop in GR signaling, coincided with the development of cutaneous atrophy in humans and mice. Using FKBP51 KO mice, we discovered that FKBP51 acts as atrophogene, as in its absence all skin compartments and epidermal follicular SCs became protected from the hypoplastic effects of glucocorticoids.

The resistance of FKBP51 KO mice to steroidinduced skin atrophy was unexpected as FKBP51 is generally thought to be a negative regulator of GR activity $[16,17]$. As a molecular chaperone that binds GR/Hsp90 heterocomplexes, FKBP51 has been shown to reduce GR affinity for ligands, to interfere with nuclear localization of receptor complexes under hormone-free conditions, and to alter GR phosphorylation [16, 18]. In light of these data, the lack of changes in GR phosphorylation at activating Ser211 in FKBP51 KO HaCaT keratinocytes was surprising. Equally unexpected was the lack of increased GR function in skin of FKBP51 KO mice and in keratinocytes after FKBP51 knockout suggesting that the concept of FKBP51 as a global negative regulator of GR should be revisited.

FKBP51 is a multi-functional protein: in addition to chaperoning steroid receptors, it negatively regulates activity of other signaling pathways such as Akt and mTOR, critical for protein synthesis and cell proliferation [19]. We report here that the levels of phospho-Akt ${ }^{\mathrm{Ser} 473}$, phospho-mTOR ${ }^{\mathrm{Ser} 2488}$ and phosphorylated downstream mTOR pro-proliferative effectors S6K1 and rpS6 were elevated in human keratinocytes lacking FKBP51 in vitro and in FKBP51 KO mouse skin in vivo.

The negative cross-talk between anabolic mTOR/ Akt and catabolic GR signaling and inhibition of GR function by mTOR are well known in different tissues including muscle [13]. We recently showed that GR function is impaired in skin lacking mTOR/Akt inhibitor DDIT4/REDD1 [27]. The inhibitory effect of mTOR/Akt on GR could be mediated via direct phosphorylation of GR at Ser134, which negatively regulates GR activity [39]. Thus, increased activation of Akt/mTOR pro-metabolic/ pro-proliferative signaling may help to explain the lack of GR activation as well as the protection of $\mathrm{CD} 34^{+}$stem cells, keratinocytes, dermal fibroblasts and adipocytes from glucocorticoids in FKBP51 KO mice.

Importantly, despite the increased activity of proproliferative Akt/mTOR signaling in the skin of FKBP51 $\mathrm{KO}$ mice, we observed only mild skin hyperplasia in these animals, and neither young nor aged FKBP51 KOs developed any cutaneous cancer lesions (data not shown). It is known that FKBP51 plays the important tissue-specific role in cancer development, and in skin it positively regulates melanoma stemness, growth, and metastatic potential [40-41]. However, its role in non-melanoma skin carcinogenesis remains to be investigated.

Interestingly, we identified recently another major target of glucocorticoids/GR, DDIT4/REDD1 (regulated in development and DNA damage response 1), as an atrophogene in skin [27, 38]. Like FKBP51, REDD1 is also a negative regulator of mTOR/Akt signaling $[42,43]$, and its genetic or pharmacological blockage spared skin from steroid-induced atrophy [27, 38]. Here we show that GR-mediated expression of REDD1 was unchanged in FKBP51 KO keratinocytes suggesting that down-regulation of FKBP51 alone is sufficient for partial resistance of skin to steroid-induced atrophy.

Overall, our studies highlight the complex, cell context-dependent regulation of GR function by 
WB

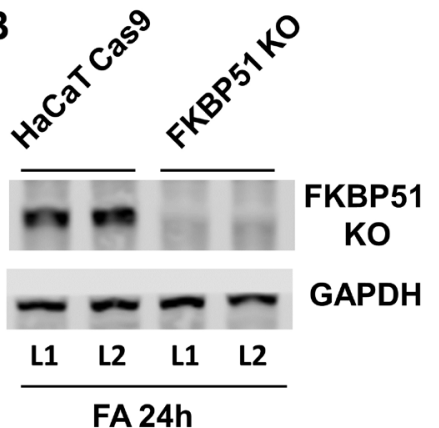

b

\begin{tabular}{|c|c|c|}
\hline WB & $\begin{array}{c}\text { HaCaT } \\
\text { Cas } 9\end{array}$ & $\begin{array}{c}\text { FKBP51 } \\
\text { KO }\end{array}$ \\
\hline 1 & $\begin{array}{lll}0 & 1 & 4\end{array}$ & $\begin{array}{lll}0 & 1 & 4\end{array}$ \\
\hline
\end{tabular}

$\begin{array}{llllll}1 & 3.4 & 2.8 & 1 & 3.4 & 2.9\end{array}$

$1--1--7$

$1 \quad 6.25 .20 .96 .35 .2$

- - - - -

11.11 .21 .51 .71 .9

-ーー - -

$=\approx \approx=\pi=$

$\begin{array}{llllll}1 & 0.9 & 1 & 1.6 & 1.2 & 1.1\end{array}$

$-\rightarrow-m-\longrightarrow$

$\begin{array}{llll}1 & 1.1 & 1.11 .81 .5 & 1.7\end{array}$

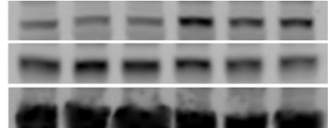

C

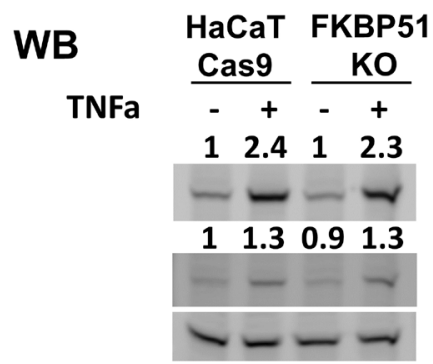

c
GR/Lamin ratio

GR, NF

p-GR/Lamin ratio

p-GR ${ }^{\text {Ser211 }}, N F$

Lamin, NF

p-AKT/AKT ratio

p-AKT ${ }^{\text {Ser473 }}$, CF

AKT, CF

p-mTOR/mTOR ratio

p-mTOR ${ }^{\mathrm{Ser} 2448}, \mathrm{CF}$

MTOR, CF

p-p70/p70 ratio

p-p70 ${ }^{\text {Thr389 }}$, CF

p70, CF

Tubulin, CF 
FKBP51. Our results also imply that targeting of GRdependent genes causatively involved in skin atrophy, such as FKBP51, could be a potential strategy to reduce/ alleviate glucocorticoid-associated skin atrophy in the clinic.

Taking into consideration the potential anti-cancer effect of FKBP51 inhibition in skin [40] and similarity between atrophic processes in aged skin and skin chronically treated with glucocorticoids [44, 45], the same strategy could be relevant to a safe skin protection against aging. Importantly, FKBP51 belongs to the group of the genes whose expression in skin depends on age [46]. Since FKBP51 has been implicated in different neurological disorders, including post-traumatic stress disorder and Alzheimer's disease [18], efforts are already underway to develop FKBP51-specific inhibitors [47-48].

\section{MATERIALS AND METHODS}

\section{Chemicals}

FA and all other chemicals unless stated otherwise were purchased from Sigma (St. Louis, MO). CBP $(0.05 \%$ cream) was purchased at the pharmacy.

\section{Animals and treatments}

B6x129 (F1 C57BL/6 X 129SvEv) and C57Bl/6 wild-type (WT) mice were from Taconic (Germantown, NY). FKBP51 KO mice on B6x129 genetic background were generated by an insertional mutation in intron 4 of the Fbkp5 gene [26]. Later transgene was transferred into C57Bl/6 genetic background. Seven-wk old mice were shaved and treated 3 days later. FA was applied topically (2 $\mu \mathrm{g} / 200 \mu \mathrm{l}$ acetone) to the back skin once or 4 times every third day for two weeks as described [14]. Control animals were treated with acetone only. Skin was harvested 4-24 h after the last application as indicated in the Figure legends. Mice were injected ip with $\mathrm{BrdU}$ (50 $\mu \mathrm{g} / \mathrm{g}$ body weight) 1 $\mathrm{h}$ before sacrifice. For biochemical studies, epidermis and subcutaneous fat were mechanically isolated from the skin by scraping [14].

All animal experiments were approved by the Northwestern University Animal Care and Use Committee.

\section{Human volunteers}

CBP cream $(0.05 \%)$ was applied topically to the inner skin of the upper right arm of healthy human volunteers (age 32-45) once. Untreated left arm skin was used as control. Five mm punch skin biopsies were taken $24 \mathrm{~h}$ after CBP application and processed for RNA extraction or formalin-fixed for immunohistochemistry. All human studies were approved by Northwestern University Institutional Review Board. Written informed consent was received from the volunteers before participation.

\section{Human keratinocyte cell cultures}

HaCaT human keratinocyte cells are in vitro spontaneously-immortalized keratinocytes from histologically normal human skin [49]. Cells were kindly provided by Dr. K. Green (Northwestern University, Chicago). HaCaT cells were cultured in Dulbecco's Modified Eagle medium containing 10\% FBS (Cellgro; Manassas, VA) and antibiotics.

\section{Knockout of FKBP51 expression by CRISPR/ Cas9 gene-editing}

CRISPR/Cas9 gene-editing was used to ablate FKBP51 in HaCaT cells. Recombinant Cas9 protein and CRISPR crRNA were purchased from Integrated DNA Technologies (Coralville, IA). The gRNAs were designed using publicly accessible engines (http:// crispr.mit.edu/; http://chopchop.cbu.uib.no/ (http:// www.uib.no/en/persons/) as described [50-52]. Only top ranked gRNA with no off-target effects confirmed by two design sites were selected for the knock-out procedure (gRNA1, FKBP51 exon 2, ATTACCTCCAAAAAAGACAG; gRNA2, FKBP51 Exon 3, GGTGAGGAAACGCCGATGAT; gRNA3, FKBP51 Exon 4, GTCATCAAGGCATGGGACAT). $\mathrm{HaCaT}$ cells were transiently transfected with ribonucleoprotein complex (RNPC) using RNAi-Max transfection reagent (Fisher Scientific). The advantages of RNPC (with Cas9 protein and synthetic gRNAs) versus standard vector-based CRISPR approaches include rapid RNPC degradation after gene editing resulting in minimal Cas9-gRNA off-target effects and cytotoxicity. Singlecell colonies were established from CRISPR-edited cell cultures and analyzed by sequencing and Western blotting to verify the knock-out of FKBP51 gene. Cas9only-treated cells were used as a control. Experiments were performed in two different FKBP51 KO clones (L1 and L2).

\section{Histological analysis and immunostaining}

Formalin-fixed, paraffin-embedded skin sections were stained with hematoxylin and eosin (H\&E) and/ or antibodies against BrdU (BD Biosciences; San Jose, CA), keratinocyte differentiation markers keratins 5 and 10 and loricrin (Covance; Greenfield, IN), FKBP51 and GR (Santa Cruz; Dallas, TX), phospho-mTORSer ${ }^{244}$, phospho-Akt ${ }^{\mathrm{Ser} 473}$ (Cell Signaling; Danvers, MA), stem cell marker CD34 (Abcam; Cambridge, MA) and Masson's trichrome to assess dermal collagen density/organization.

Quantification of the epidermal and dermal adipose thicknesses (as the readouts for skin thinning) was performed in H\&E stained skin sections. At least 10 individual fields/slide in three individual samples/ experimental group were counted using Axioplan2 
microscope software (Carl Zeiss). To assess keratinocyte proliferation, the number of proliferating $\left(\mathrm{BrdU}^{+}\right)$and total basal keratinocytes was counted in 10 individual fields/ slide of each sample.

To assess the effect of FA on the expression of CD34 stem cell marker, we examined $\sim 100$ hair follicles in the skin samples of each genotype (3 individual skin samples/ group). Hair follicles with $\geq 5 \mathrm{CD} 34+$ cells in the bulge, were considered positive.

\section{Western blot analysis}

Whole cell protein extracts were prepared as described [27]. Separate cytoplasmic and nuclear protein fractions were isolated with NE-PER Nuclear and Cytoplasmic Extraction Kit according to manufacturer protocol (ThermoFisher Scientific, Waltham, MA). The proteins were resolved by SDS-PAGE and transferred to nitrocellulose membranes (LI-COR Biosciences; Lincoln, $\mathrm{NE}$ ). After blocking, membranes were incubated with primary antibodies overnight at $4{ }^{\circ} \mathrm{C}$, followed by IRDye ${ }^{\circledR}$ secondary antibodies (LI-COR Biosciences). LI-COR Odyssey Imager was used for the band visualization. The antibodies against FKBP51, GR, RelA/p65, p65 ${ }^{\text {Ser536 }}$ (Santa Cruz Biotechnology, Dallas, TX), Redd1 (Proteintech; Chicago, IL), phospho-GR ${ }^{\text {Ser211 }}$, Akt, phospho-Akt ${ }^{\text {Ser473, }}$

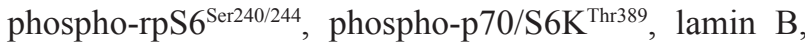
tubulin (Cell Signaling, Danvers, MA), and GAPDH (Sigma, St Louis, MO) were used at concentrations recommended by their manufacturers. The multi-band pattern of FKBP51 signal on Western blots (Figure 1a) may reflect FKBP51 post-translational modifications such as phosphorylation [41].

ImageJ (http://rsb.info.nih.gov/ij/index.html) was used for densitometry. The intensity of bands was normalized to the corresponding loading control and expressed as fold of change vs vehicle-treated WT or Cas9-only control.

\section{RNA preparation and PCR}

RNA from whole human skin, murine epidermis and keratinocyte cultures were isolated with RiboPure kit (Ambion/Life Technologies; Grand Island, NY), and from subcutaneous adipose with RNeasy Lipid Tissue Kit (Qiagen; Germantown, MD) and treated with TURBO $^{\text {TM }}$ DNase (Ambion). Purity of RNA samples from epidermis and subcutaneous fat was confirmed by keratinocyte and adipose cell markers expression. Gene expression was assessed using semi-quantitative two-step RT-PCR and quantitative real-time PCR (qPCR). Reverse transcription was performed using $1 \mu \mathrm{g}$ RNA, random hexamers and M-MLV reverse transcriptase (Invitrogen/ Life Technologies), according to manufacturer instructions as described [27]. The gene-specific primers were designed with NCBI Primer-BLAST as described [27,
38]. qPCR with SYBR Green detection was performed on the LightCycler ${ }^{\circledR} 96$ Real-Time PCR instrument (Roche Diagnostics, Indianapolis, IN). Each sample was tested in triplicate. The results were normalized to the expression of the housekeeping Rpl27 gene [53].

\section{Statistical analysis}

Mean and standard deviation (SD) values were calculated using Microsoft Excel software. The treatment effects in each experiment were compared by t-test using the GraphPad (La Jolla, CA) statistical software package. Differences between groups were considered significant at $\mathrm{P}<0.05$. All experiments were repeated 2-3 times. In animal experiments we used 3-4 mice per experimental group. In all figures, the results of one representative experiment are shown as means $\pm \mathrm{SD}$.

\section{Abbreviations}

BrdU, 5-bromo-2'-deoxyuridine; CBP, clobetasol propionate; CRISPR, Clustered Regularly Interspaced Short Palindromic Repeats; FA, fluocinolone acetonide; FKBP51, FK506-binding protein 51; GAPDH, glyceraldehyde 3-phosphate dehyddrogenase; GR, glucocorticoid receptor; K5, keratin-5; K10, keratin-10; $\mathrm{KO}$, knockout; MAPK, mitogen-activated protein kinase; mTOR, mammalian target of rapamycin; NF$\kappa \mathrm{B}$, nuclear factor-kB; PDK1, 3-phosphoinositidedependent protein kinase 1; PHLPP, pleckstrin homology domain leucine-rich repeat protein phosphatase; PI3K, phosphatidylinositol 3-kinase; PPIase, cis-trans peptidylprolyl isomerase; qPCR, quantitative real-time reversetranscribed polymerase chain reaction; Rpl27, ribosomal protein L27; rpS6, ribosomal protein S6; S6K1, ribosomal p70/S6 kinase 1; SC, stem cell; WT, wild-type.

\section{Author contributions}

IB, ERS, WS and JTD designed the experiments; $\mathrm{AY}$ and $\mathrm{PB}$ designed gRNAs and strategy to generate FKBP51 KO cells; GB, PB, AY and LAS performed the experiments; JTD and BR performed statistical and bioinformatics analysis; IB and ERS wrote the paper; GB contributed to writing and generated figures.

\section{ACKNOWLEDGMENTS AND FUNDING}

This work was supported by R01GM112945, R01AI125366 (to IB and JTD), Foglia family foundation grant (to IB), DK111826 (to ERS), and ADA grant \#117-PDF-067 (to LAS). We are thankful to NU SDRC pathology and DNA/RNA delivery cores and MD Anderson Science Park Histology Core for technical consultations and support. 


\section{CONFLICTS OF INTEREST}

The authors state no conflicts of interests.

\section{REFERENCES}

1. Slominski A, Zjawiony J, Wortsman J, Semak I, Stewart J, Pisarchik A, Sweatman T, Marcos J, Dunbar C, C Tuckey R. A novel pathway for sequential transformation of 7-dehydrocholesterol and expression of the P450scc system in mammalian skin. Eur J Biochem. 2004; 271:4178-88. https://doi.org/10.1111/j.1432-1033.2004.04356.x.

2. Slominski A, Zbytek B, Szczesniewski A, Semak I, Kaminski J, Sweatman T, Wortsman J. CRH stimulation of corticosteroids production in melanocytes is mediated by ACTH. Am J Physiol Endocrinol Metab. 2005; 288:E70106. https://doi.org/10.1152/ajpendo.00519.2004.

3. Slominski AT, Manna PR, Tuckey RC. On the role of skin in the regulation of local and systemic steroidogenic activities. Steroids. 2015; 103:72-88. https://doi.org/10.1016/j. steroids.2015.04.006.

4. Sevilla LM, Pérez P. Roles of the glucocorticoid and mineralocorticoid receptors in skin pathophysiology. Int J Mol Sci. 2018; 19:1906. https://doi.org/10.3390/ ijms19071906.

5. Sarkar MK, Kaplan N, Tsoi LC, Xing X, Liang Y, Swindell WR, Hoover P, Aravind M, Baida G, Clark M, Voorhees JJ, Nair RP, Elder JT, et al. Endogenous Glucocorticoid Deficiency in Psoriasis Promotes Inflammation and Abnormal Differentiation. J Invest Dermatol. 2017; 137:1474-83. https://doi.org/10.1016/j.jid.2017.02.972.

6. Hengge UR, Ruzicka T, Schwartz RA, Cork MJ. Adverse effects of topical glucocorticosteroids. J Am Acad Dermatol. 2006; 54:1-15. https://doi.org/10.1016/j.jaad.2005.01.010.

7. Samarasekera EJ, Sawyer L, Wonderling D, Tucker R, Smith $\mathrm{CH}$. Topical therapies for the treatment of plaque psoriasis: systematic review and network meta-analyses. Br J Dermatol. 2013; 168:954-67. https://doi.org/10.1111/bjd.12276.

8. Lehmann $\mathrm{P}$, Zheng $\mathrm{P}$, Lavker RM, Kligman AM. Corticosteroid atrophy in human skin. A study by light, scanning, and transmission electron microscopy. J Invest Dermatol. 1983; 81:169-76. https://doi.org/10.1111/15231747.ep12543603.

9. Schoepe S, Schäcke H, Asadullah K. Test systems for the determination of glucocorticoid receptor ligand induced skin atrophy. Dermatoendocrinol. 2011; 3:175-79. https:// doi.org/10.4161/derm.15065.

10. Schoepe S, Schäcke H, May E, Asadullah K. Glucocorticoid therapy-induced skin atrophy. Exp Dermatol. 2006; 15:40620. https://doi.org/10.1111/j.0906-6705.2006.00435.x.

11. Oakley RH, Cidlowski JA. The biology of the glucocorticoid receptor: new signaling mechanisms in health and disease. J Allergy Clin Immunol. 2013; 132:1033-44. https://doi. org/10.1016/j.jaci.2013.09.007.
12. Leis H, Page A, Ramírez A, Bravo A, Segrelles C, Paramio J, Barettino D, Jorcano JL, Pérez P. Glucocorticoid receptor counteracts tumorigenic activity of Akt in skin through interference with the phosphatidylinositol 3-kinase signaling pathway. Mol Endocrinol. 2004; 18:303-11. https://doi.org/10.1210/me.2003-0350.

13. Shimizu N, Yoshikawa N, Ito N, Maruyama T, Suzuki Y, Takeda S, Nakae J, Tagata Y, Nishitani S, Takehana K, Sano M, Fukuda K, Suematsu M, et al. Crosstalk between glucocorticoid receptor and nutritional sensor mTOR in skeletal muscle. Cell Metab. 2011; 13:170-82. https://doi. org/10.1016/j.cmet.2011.01.001.

14. Chebotaev D, Yemelyanov A, Zhu L, Lavker RM, Budunova I. The tumor suppressor effect of the glucocorticoid receptor in skin is mediated via its effect on follicular epithelial stem cells. Oncogene. 2007; 26:3060-68. https://doi.org/10.1038/ sj.onc. 1210108 .

15. Sevilla LM, Bayo P, Latorre V, Sanchis A, Pérez P. Glucocorticoid receptor regulates overlapping and differential gene subsets in developing and adult skin. Mol Endocrinol. 2010; 24:2166-78. https://doi.org/10.1210/ me.2010-0183.

16. Stechschulte LA, Sanchez ER. FKBP51-a selective modulator of glucocorticoid and androgen sensitivity. Curr Opin Pharmacol. 2011; 11:332-37. https://doi. org/10.1016/j.coph.2011.04.012.

17. Jääskeläinen $\mathrm{T}$, Makkonen $\mathrm{H}$, Palvimo JJ. Steroid up-regulation of FKBP51 and its role in hormone signaling. Curr Opin Pharmacol. 2011; 11:326-31. https://doi. org/10.1016/j.coph.2011.04.006.

18. Storer CL, Dickey CA, Galigniana MD, Rein T, Cox MB. FKBP51 and FKBP52 in signaling and disease. Trends Endocrinol Metab. 2011; 22:481-90. https://doi. org/10.1016/j.tem.2011.08.001.

19. Davies TH, Ning YM, Sánchez ER. A new first step in activation of steroid receptors: hormone-induced switching of FKBP51 and FKBP52 immunophilins. J Biol Chem. 2002; 277:4597-600. https://doi.org/10.1074/jbc.C100531200.

20. Wang L. FKBP51 regulation of AKT/protein kinase B phosphorylation. Curr Opin Pharmacol. 2011; 11:360-64. https://doi.org/10.1016/j.coph.2011.03.008.

21. Fabian AK, März A, Neimanis S, Biondi RM, Kozany C, Hausch F. InterAKTions with FKBPs - mutational and pharmacological exploration. PLoS One. 2013; 8:e57508. https://doi.org/10.1371/journal.pone.0057508.

22. Pei H, Li L, Fridley BL, Jenkins GD, Kalari KR, Lingle W, Petersen G, Lou Z, Wang L. FKBP51 affects cancer cell response to chemotherapy by negatively regulating Akt. Cancer Cell. 2009; 16:259-66. https://doi.org/10.1016/j. ccr.2009.07.016.

23. März AM, Fabian AK, Kozany C, Bracher A, Hausch F. Large FK506-binding proteins shape the pharmacology of rapamycin. Mol Cell Biol. 2013; 33:1357-67. https://doi. org/10.1128/MCB.00678-12. 
24. Erlejman AG, De Leo SA, Mazaira GI, Molinari AM, Camisay MF, Fontana V, Cox MB, Piwien-Pilipuk G, Galigniana MD. NF- $\mathrm{BB}$ transcriptional activity is modulated by FK506-binding proteins FKBP51 and FKBP52: a role for peptidyl-prolyl isomerase activity. J Biol Chem. 2014; 289:26263-76. https://doi.org/10.1074/jbc.M114.582882.

25. Romano S, Mallardo M, Romano MF. FKBP51 and the $N F-\kappa B$ regulatory pathway in cancer. Curr Opin Pharmacol. 2011; 11:288-93. https://doi.org/10.1016/j. coph.2011.04.011.

26. Yong W, Yang Z, Periyasamy S, Chen H, Yucel S, Li W, Lin LY, Wolf IM, Cohn MJ, Baskin LS, Sánchez ER, Shou W. Essential role for Co-chaperone Fkbp52 but not Fkbp51 in androgen receptor-mediated signaling and physiology. J Biol Chem. 2007; 282:5026-36. https://doi.org/10.1074/jbc. M609360200.

27. Baida G, Bhalla P, Kirsanov K, Lesovaya E, Yakubovskaya M, Yuen K, Guo S, Lavker RM, Readhead B, Dudley JT, Budunova I. REDD1 functions at the crossroads between the therapeutic and adverse effects of topical glucocorticoids. EMBO Mol Med. 2015; 7:42-58. https:// doi.org/10.15252/emmm.201404601.

28. Stechschulte LA, Hinds TD Jr, Khuder SS, Shou W, Najjar SM, Sanchez ER. FKBP51 controls cellular adipogenesis through p38 kinase-mediated phosphorylation of GR $\alpha$ and PPAR $\gamma$. Mol Endocrinol. 2014; 28:1265-75. https://doi. org/10.1210/me.2014-1022.

29. Stechschulte LA, Qiu B, Warrier M, Hinds TD Jr, Zhang M, Gu H, Xu Y, Khuder SS, Russo L, Najjar SM, LeckaCzernik B, Yong W, Sanchez ER. FKBP51 Null Mice Are Resistant to Diet-Induced Obesity and the PPAR $\gamma$ Agonist Rosiglitazone. Endocrinology. 2016; 157:3888-900. https:// doi.org/10.1210/en.2015-1996.

30. Chebotaev DV, Yemelyanov AY, Lavker RM, Budunova IV. Epithelial cells in the hair follicle bulge do not contribute to epidermal regeneration after glucocorticoid-induced cutaneous atrophy. J Invest Dermatol. 2007; 127:2749-58. https://doi.org/10.1038/sj.jid.5700992.

31. Audet-Walsh E, Anderson A. Dexamethasone induction of murine CYP2B genes requires the glucocorticoid receptor. Drug Metab Dispos. 2009; 37:580-88. https://doi. org/10.1124/dmd.108.022772.

32. Cheng Q, Morand E, Yang YH. Development of novel treatment strategies for inflammatory diseases-similarities and divergence between glucocorticoids and GILZ. Front Pharmacol. 2014; 5:169. https://doi.org/10.3389/ fphar.2014.00169.

33. Wang Z, Rong YP, Malone MH, Davis MC, Zhong F, Distelhorst CW. Thioredoxin-interacting protein (txnip) is a glucocorticoid-regulated primary response gene involved in mediating glucocorticoid-induced apoptosis. Oncogene. 2006; 25:1903-13. https://doi.org/10.1038/sj.onc.1209218. Erratum in: Oncogene. 2008 Feb 21;27(9):1342.

34. Holz MK, Blenis J. Identification of S6 kinase 1 as a novel mammalian target of rapamycin (mTOR)-phosphorylating kinase. J Biol Chem. 2005; 280:26089-93. https://doi. org/10.1074/jbc.M504045200.

35. Meyuhas $\mathrm{O}$, Dreazen A. Ribosomal protein $\mathrm{S} 6$ kinase from TOP mRNAs to cell size. Prog Mol Biol Transl Sci. 2009; 90:109-53. https://doi.org/10.1016/ S1877-1173(09)90003-5.

36. Zhou H, Huang S. Role of mTOR signaling in tumor cell motility, invasion and metastasis. Curr Protein Pept Sci. 2011; 12:30-42. https://doi. org/10.2174/138920311795659407.

37. Stechschulte LA, Hinds TD Jr, Ghanem SS, Shou W, Najjar SM, Sanchez ER. FKBP51 reciprocally regulates GR $\alpha$ and PPAR $\gamma$ activation via the Akt-p38 pathway. Mol Endocrinol. 2014; 28:1254-64. https://doi.org/10.1210/me.2014-1023.

38. Lesovaya E, Agarwal S, Readhead B, Vinokour E, Baida G, Bhalla P, Kirsanov K, Yakubovskaya M, Platanias LC, Dudley JT, Budunova I. Rapamycin Modulates Glucocorticoid Receptor Function, Blocks Atrophogene REDD1, and Protects Skin from Steroid Atrophy. J Invest Dermatol. 2018; 138:1935-44. https://doi.org/10.1016/j. jid.2018.02.045.

39. Piovan E, Yu J, Tosello V, Herranz D, Ambesi-Impiombato A, Da Silva AC, Sanchez-Martin M, Perez-Garcia A, Rigo I, Castillo M, Indraccolo S, Cross JR, de Stanchina E, et al. Direct reversal of glucocorticoid resistance by AKT inhibition in acute lymphoblastic leukemia. Cancer Cell. 2013; 24:766-76. https://doi.org/10.1016/j.ccr.2013.10.022.

40. Romano S, Staibano S, Greco A, Brunetti A, Nappo G, Ilardi G, Martinelli R, Sorrentino A, Di Pace A, Mascolo M, Bisogni R, Scalvenzi M, Alfano B, Romano MF. FK506 binding protein 51 positively regulates melanoma stemness and metastatic potential. Cell Death Dis. 2013; 4:e578. https://doi.org/10.1038/cddis.2013.109.

41. Fries GR, Gassen NC, Rein T. The FKBP51 glucocorticoid receptor co-chaperone: regulation, function, and implications in health and disease. Int J Mol Sci. 2017; 18:2614. https://doi.org/10.3390/ijms18122614.

42. DeYoung MP, Horak P, Sofer A, Sgroi D, Ellisen LW. Hypoxia regulates TSC1/2-mTOR signaling and tumor suppression through REDD1-mediated 14-3-3 shuttling. Genes Dev. 2008; 22:239-51. https://doi.org/10.1101/ gad.1617608.

43. Dennis MD, Coleman CS, Berg A, Jefferson LS, Kimball SR. REDD1 enhances protein phosphatase 2A-mediated dephosphorylation of Akt to repress mTORC1 signaling. Sci Signal. 2014; 7:ra68. https://doi.org/10.1126/ scisignal.2005103.

44. Dobos G, Lichterfeld A, Blume-Peytavi U, Kottner J. Evaluation of skin ageing: a systematic review of clinical scales. Br J Dermatol. 2015; 172:1249-61. https://doi. org/10.1111/bjd.13509.

45. Rittié L, Fisher GJ. Natural and sun-induced aging of human skin. Cold Spring Harb Perspect Med. 2015; 5:a015370. https://doi.org/10.1101/cshperspect.a015370. 
46. Glass D, Viñuela A, Davies MN, Ramasamy A, Parts L, Knowles D, Brown AA, Hedman AK, Small KS, Buil A, Grundberg E, Nica AC, Di Meglio P, et al, and MuTHER consortium. Gene expression changes with age in skin, adipose tissue, blood and brain. Genome Biol. 2013; 14:R75. https://doi.org/10.1186/gb-2013-14-7-r75.

47. Blackburn EA, Walkinshaw MD. Targeting FKBP isoforms with small-molecule ligands. Curr Opin Pharmacol. 2011; 11:365-71. https://doi.org/10.1016/j.coph.2011.04.007.

48. Gaali S, Kirschner A, Cuboni S, Hartmann J, Kozany C, Balsevich G, Namendorf C, Fernandez-Vizarra P, Sippel C, Zannas AS, Draenert R, Binder EB, Almeida OF, et al. Selective inhibitors of the FK506-binding protein 51 by induced fit. Nat Chem Biol. 2015; 11:33-37. https://doi. org/10.1038/nchembio.1699.

49. Boukamp P, Petrussevska RT, Breitkreutz D, Hornung J, Markham A, Fusenig NE. Normal keratinization in a spontaneously immortalized aneuploid human keratinocyte cell line. J Cell Biol. 1988; 106:761-71. https://doi. org/10.1083/jcb.106.3.761.
50. Hsu PD, Scott DA, Weinstein JA, Ran FA, Konermann S, Agarwala V, Li Y, Fine EJ, Wu X, Shalem O, Cradick TJ, Marraffini LA, Bao G, Zhang F. DNA targeting specificity of RNA-guided Cas9 nucleases. Nat Biotechnol. 2013; 31:827-32. https://doi.org/10.1038/nbt.2647.

51. Labun K, Montague TG, Gagnon JA, Thyme SB, Valen E. CHOPCHOP v2: a web tool for the next generation of CRISPR genome engineering. Nucleic Acids Res. 2016; 44:W272-6. https://doi.org/10.1093/nar/gkw398.

52. Montague TG, Cruz JM, Gagnon JA, Church GM, Valen E. CHOPCHOP: a CRISPR/Cas9 and TALEN web tool for genome editing. Nucleic Acids Res. 2014; 42:W401-7. https://doi.org/10.1093/nar/gku410.

53. de Jonge HJ, Fehrmann RS, de Bont ES, Hofstra RM, Gerbens F, Kamps WA, de Vries EG, van der Zee AG, te Meerman GJ, ter Elst A. Evidence based selection of housekeeping genes. PLoS One. 2007; 2:e898. https://doi. org/10.1371/journal.pone.0000898. 